\title{
Bar Locator Versus Bar Clip Attachment for Implant Assisted Mandibular Overdenture
}

\section{Shady M, Emera R, Hegazy SA* and Kenawy M}

Faculty of Dentistry, Mansoura University, Egypt

\begin{abstract}
Objectives: To compare Bar-locator attachment versus Bar-clip attachment for retaining two implants assisted complete mandibular overdenture regarding masticatory efficiency and retention.

Materials and methods: Sixteen healthy completely edentulous male patients were selected for this study. Each patient received two inter-foraminal implants in the canine areas of the mandible using standardized two-stage surgical technique. Implants left unloaded for three months. The patients were randomly classified according to type of bar attachment into two equal groups, Group (I) using Bar-locator attachment) and Group (II) using Bar-clip attachment. Masticatory efficiency and retention were evaluated using unmixed two colored chewing gums and digital force meter respectively. Evaluations were performed at time of insertion (T0), 3 months (T3) and 6 months (T6) after insertion.

Results: Regarding masticatory efficiency, both groups showed decrease in number of unmixed fraction as number of chewing strokes increased. In Group I, number of unmixed fraction significantly decreased with advance time, while in group II, the number of unmixed fraction significantly increased with advance time. Group I showed significant increase in number of unmixed fraction in most of chewing strokes at T0 and significant decrease in number of unmixed fraction at T3, T6 than in Group II. Regarding retention (measured in Newton N),it decreased significantly with advance of time, Group I (Bar-locator attachment) showed a statistically significant increased retention values (R) compared to Group II at different observation times
\end{abstract}

Conclusion: Both types of bar attachment provided sufficient values in terms of retention and masticatory efficiency. However, bar-locator retained overdenture is considered a promising prosthesis regarding retention and long term masticatory efficiency.

Keywords: Bar clip; Bar locator; Overdenture

\section{Introduction}

Implant assisted overdentures have been widely used to improve low retention and stability of complete dentures. Attachment to the implants improves the stability and function of the prostheses and increases patient satisfaction $[1,2]$. The implant assisted overdentures also improves neuromuscular activity and adaptation and thereby substantially improves masticatory function in edentulous patients $[3,4]$.

The two implant mandibular overdenture is the least costly implant option; it offers a significant increase in retention and stability over a complete denture and demonstrates a considerable improvement in quality of life. For these reasons, two implant assisted overdenture is considered the standard of care for edentulous mandibles $[5,6]$.

Implant-assisted overdentures may use a variety of splinted bar attachment systems or incorporate a variety of individual abutmentbased attachments called stud attachments (ball, magnets, telescopic), resilient stud attachments (Locators, ERA) and non-resilient stud attachments [7].

Bar attachment has the advantage of splinting implants together and act to inhibit displacing forces in vertical and oblique directions [8]. However, bars increase cost of overdentures, require more space and don't significantly improve retention and stability over solitary attachments [9].

The Bar-locator Attachment System can be particularly useful in treating completely edentulous patients [10]. Bar-overdentures offer the benefit of splinting the implants within the arch for removable applications and incorporated Locator attachments provide better stability and retention than freestanding attachments [11].

Incorporating a locator attachment as a retentive component has several advantages over other systems. Locator attachments provide dual retention through both external and internal mating surfaces, a self-aligning feature which is helpful in guiding patients when placing their denture and can be combined with guide planes on a milled bar for a common path of insertion. Locator attachments require low maintenance and offer high durability and long lasting performance for over 60,000 insertion cycles (equivalent to 10 years of clinical function) [12].

This work aimed to evaluate retention and chewing efficiency of mandibular overdenture retained by two intra-foraminal osseointegrated implants with either bar-Locator attachment or barclip attachment

\section{Materials and Methods}

Sixteen healthy completely edentulous male patients were selected from the outpatient clinic of Prosthodontic Department, Faculty of dentistry, Mansoura University according to the following criteria: all patients have maxillary and mandibular residual alveolar ridge covered with healthy firm mucosa, sufficient mandibular residual alveolar ridges verified by digital panoramic $\mathrm{x}$-ray and ridge mapping, one year

*Corresponding author: Salah AbdelFatah Hegazy, Assistant Professor of removable Prosthodontics, Faculty of Dentistry, Mansoura University, Gomhorea Street, Mansoura, Dakahlia 050, Egypt, Tel: 00201227690209; Fax 0020502343020; E-mail: salahhegazy2003@yahoo.com

Received May 19, 2014; Accepted August 27, 2014; Published August 29, 2014

Citation: Shady M, Emera R, Hegazy SA, Kenawy M (2014) Bar Locator Versus Bar Clip Attachment for Implant Assisted Mandibular Overdenture. Dentistry S2 006. doi:10.4172/2161-1122.S2-006

Copyright: $\odot 2014$ Shady M, et al. This is an open-access article distributed under the terms of the Creative Commons Attribution License, which permits unrestricted use, distribution, and reproduction in any medium, provided the original author and source are credited. 
Citation: Shady M, Emera R, Hegazy SA, Kenawy M (2014) Bar Locator Versus Bar Clip Attachment for Implant Assisted Mandibular Overdenture. Dentistry S2: 006. doi:10.4172/2161-1122.S2-006

Page 2 of 5

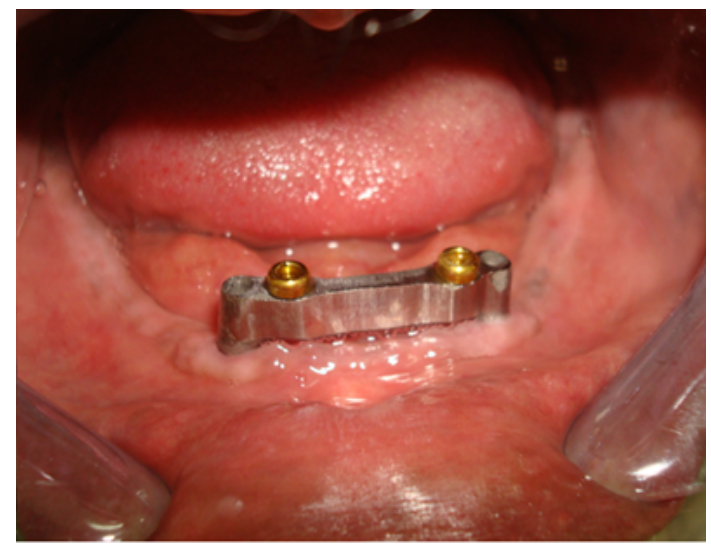

Figure 1: Group I Bar-Locator attachment.

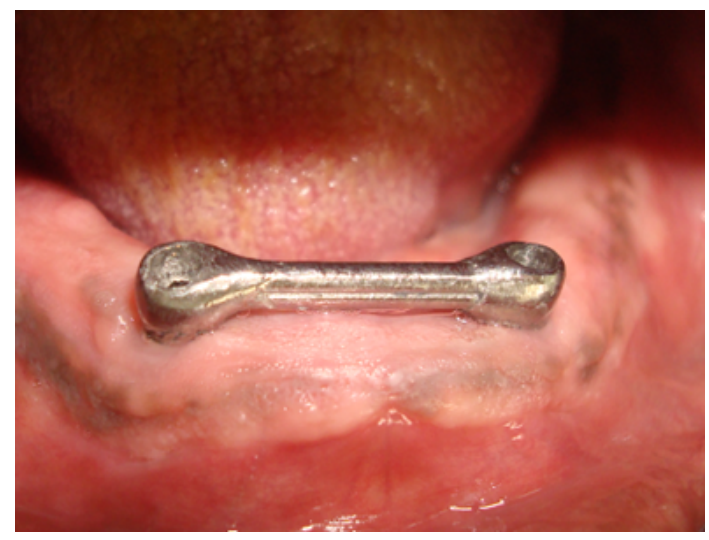

Figure 2: Group II Casted bar attachment.

at least after last extraction, no previous denture experience, Angle's class I maxillomandibular relation, sufficient inter-arch space. Exclusive criteria were parafuncional habits, smoking, alcoholism, systemic disorders affecting bone as diabetes, history of radiation therapy in the head and neck region, TMJ or neuromuscular disorders. For each patient, conventional complete denture was constructed and inserted. After one month of using denture, bone supported sterolithographic surgical guide was constructed by the aid of CT cone-beam software for exact site and angulations of dental implants to be used as a surgical guide for implants placement. After local anesthesia, two Laserlok tapered internal self-tapping dental implantsof $13 \mathrm{~mm}$ length and 3.7 $\mathrm{mm}$ width were surgically inserted in canines' areas of the mandibular residual alveolar ridge using two stage surgical techniques. A postinsertion panoramic $\mathrm{x}$-ray was made to evaluate the implant positions.

After three months of osseo-integration period the dental implants were exposed and healing abutments were placed for one week. Then open tray functional impression was made for all patients using two long transfer copings, and implant analogues were attached to the transfer coping before impression pouring. Then patients were randomly classified into two equal groups: Group (I) (Bar-locator attachment) (Figure 1): a custom made milled bar was constructed with parallel walls and the threaded site in the waxed bar was then drilled using 1.7 $\mathrm{mm}$ Bar Drill, and $2.0 \mathrm{~mm}$ Bar Tap mounted to milling machine and make 2 holes in the top surface of bar.
The locator female portion was attached using special rider. Group (II) (Bar-clip attachment) (Figure 2): a plastic ready-made multipurpose bar was casted in cobalt chrome alloy.

Bars in both groups were tried-in and new mandibular overdentures were fabricated. For Group (I) Pick up of locator male portion, metal ring was done, then pink male portion (medium retention) was used (Figure 3) and two yellow plastic clips for group (II) (Figure 4). For both groups; masticatory efficiency and retention were evaluated at time of insertion (T0), three months (T3) and six months (T6) after insertion of prosthesis.

\section{Evaluation of Masticatory Efficiency}

According to Schimmel et al. [13] Two-color chewing gum test for masticatory efficiency was used to evaluate the masticatory efficiency (Figure 5). Samples of a two-color chewing gum were prepared. Strips of $30 \mathrm{~mm}$ length were cut from both colors and manually stuck together [13], so that the test strip presented were $30 \times 18 \times 3 \mathrm{~mm}$. Patients were instructed to chew five samples of chewing gum for 5,10,20,30 and 50 chewing cycles. After chewing the gums, the samples were then spat into transparent plastic bags, which were labeled with corresponding numbers of strokes. All samples were assessed after flattening to $1 \mathrm{~mm}$ thick 'wafers'. The unmixed pixels counted using Adobe Photoshop

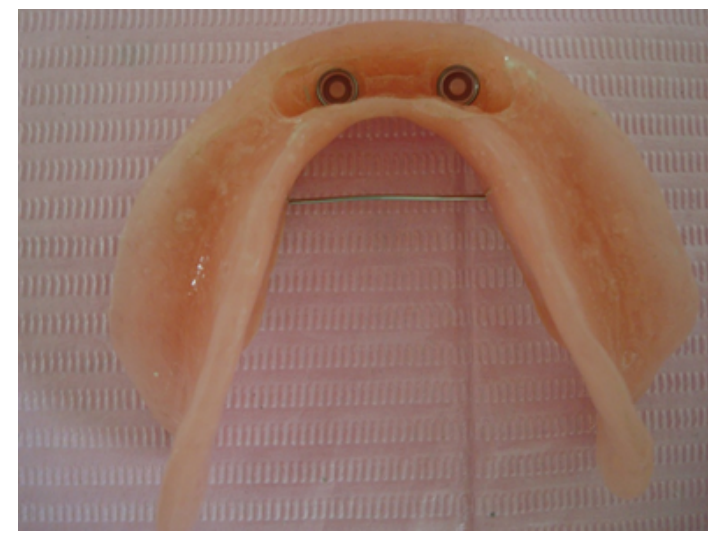

Figure 3: Fitting surface of mandibular overdenture retained by Bar-locator attachment.

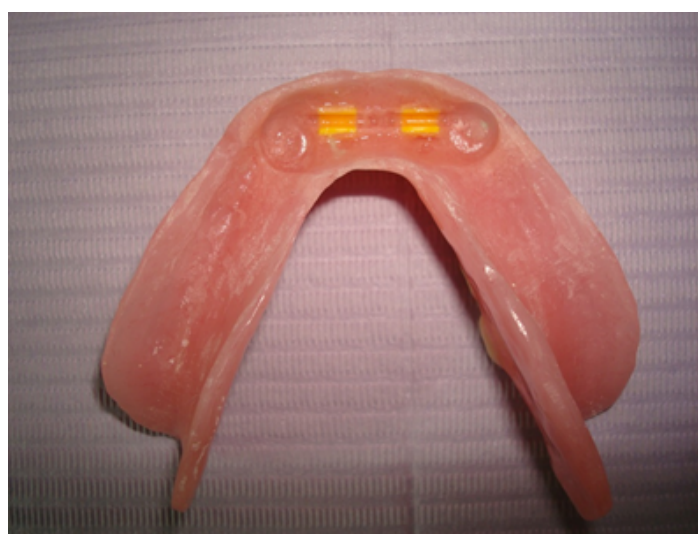

Figure 4: Fitting surface of mandibular overdenture retained by Bar-clip attachment. 
Elements ${ }^{*}$ to calculate the ratio of unmixed color to the total surface as following: The samples were scanned from both sides with a fixed resolution (500 dots per inch). The scanned image was then copied into an image of fixed size $(1175 \times 925)$ pixels and stored in Adobe Photoshop format (psd.). Then the 'magic wand' tool was used (tolerance 20,25,30) to select the unmixed white parts of the image. The numbers of selected pixels were recorded from the histogram for each side and each tolerance then mean of those figures was calculated. Subsequently a ratio was computed for the unmixed fraction (UF) using the following formula:

\section{(Pixels white side $a+$ Pixels white side $b$ )-2xPixels of scale}

\section{2xPixels all}

\section{Evaluation of Retention}

According to Burns et al. [14], the mandibular overdenture was modified so that 2 hooks were attached; one on each side at the midlabial flange, an orthodontic wire (18 guage diameter) was attached to the hooks passing over the occlusal surface of posterior teeth. Dentures were inserted intra-orally and the "pull" end of the force gauge was connected to the wire at the midpoint and adjusted to measure peak force needed to dislodge the overdenture in Newton (N) (Figure 6).

The force gauge was pulled vertically upward until denture retention was lost and the prosthesis moved vertically, and then reading was recorded 5 times and means value was calculated.

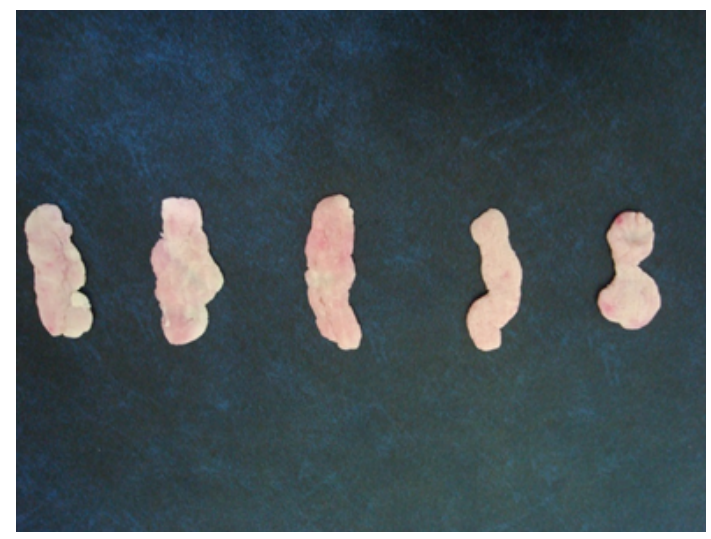

Figure 5: Five chewed 2 color chewing gum at different numbers of strokes.

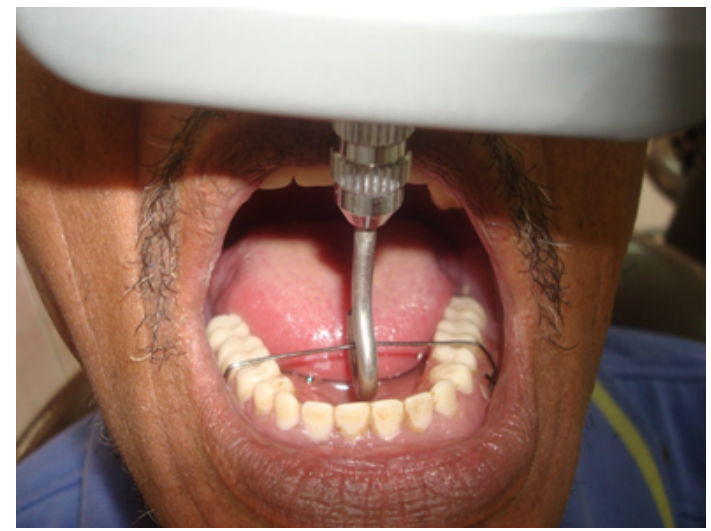

Figure 6: Clinical Retention Measurement.

\section{Statistical analysis}

The data (masticatory efficiency and retention values) did not met the normal distribution and were non parametric as indicated by Shapiro-wilk test. Unmixed fraction (UF) between different chewing strokes $(5,10,20,30$ and 50 strokes), and UF and retention values between observation times for each group were compared using the Freidman test followed by Wilcoxon's signed rank test for multiple comparisons. To compare UF and retention values between groups, the Mann- Whitney test was used. The non-parametric SpearmanRho correlation test was used to detect possible correlation between masticatory efficiency (UF) and retention for both groups. The data were analyzed using SPSS ${ }^{\circ}$ software version 18 (SPSS Inc., Chicago, IL, USA) and SAS $^{\circ}$ software version 9.2 (SAS Institute, Cary, NC, USA). Statistical significance was set at 0.05 for all analyses.

\section{Results}

There was a statistically significant difference in UF between the numbers of chewing strokes at different observation times for both groups. For both groups, the UF significantly decreased when the number of chewing strokes increased (Group I $0.2700 \pm 0.1120$ at 5 strokes and $0.0033 \pm 0.0015$ at 50 strokes), (Group II $0.0949 \pm 0.0181$ at 5 strokes and $0.0037 \pm 0.0006$ at 50 strokes). For Group I (locatorlbar attachment), the UF significantly decreased with advance time $(\mathrm{P}=0.32$ from T0-T6 at 50 strokes), while in group II the UF significantly increased advance with time ( $\mathrm{P}=0.21$ from $\mathrm{T} 0-\mathrm{T} 6$ at 50 strokes). Group I showed a significant increase in UF compared to Group II (barlclip attachment) at (T0) ( $\mathrm{P}=0.10$ at 50 strokes), (T3) ( $\mathrm{P}=0.10$ at 50 strokes), while at T6 Group I (locator bar abutments) showed a significant decrease in UF compared to Group II (barlclip attachment) $(\mathrm{P}=0.10)$ (Table 1).

There was a significant difference between observation times for both groups. For both groups, the retention values (R) decreased significantly with advance of time (Group I $24.5 \pm 2.25$ at T0 and 12.7 \pm 0.46 at T6), (Group II $19.9 \pm 0.17$ at T0 and $6.31 \pm 1.46$ at T6). Group I (locatorlbar attachment) showed a significant increase in retention values $(\mathrm{R})$ compared to GII at different observation times $(\mathrm{P}=0.018$ at T0, 0.010 at T3 and 0.022 at T6) (Table 2).

\section{Discussion}

For both groups, the unmixed fraction (UF) significantly decreased when the number of chewing strokes increased. As during chewing, the food bolus or food particles are reduced in size, mixed together and with saliva by contacting cusps of posterior teeth as postulated by Prinz et al. [15].

Weijenberg et al. [16] stated that increasing the number of chewing cycles for the same patient results in more mixing between particles of two-colored chewing gums. For Group I (locatorlbar attachment), the UF significantly decreased with advance time, while in group II the UF significantly increased advance with time. This may be due to the effect of retention and stability of the prosthesis on masticatory performance. This is in agreement with Van der Bilt et al. [17] who affirmed that good oral function depends on the retention, stability and the attachment of the denture. In Group I (locator|bar attachment) denture function increased by time due to settlement and accommodation of the denture on the resilient mucosa described.

In case of Group II (Bar-clip attachment) in vitro experiments have shown a loss of retention of $66 \%$ of the clips attached to cast bars embedded in overdentures following more than 15 removals 
Citation: Shady M, Emera R, Hegazy SA, Kenawy M (2014) Bar Locator Versus Bar Clip Attachment for Implant Assisted Mandibular Overdenture. Dentistry S2: 006. doi:10.4172/2161-1122.S2-006

Page 4 of 5

\begin{tabular}{|c|c|c|c|c|c|}
\hline & \multicolumn{5}{|c|}{ T0 } \\
\hline & 5 strokes & 10 strokes & 20 strokes & 30 strokes & 50 strokes \\
\hline $\begin{array}{l}\text { Groupl } \\
\mathrm{X} \pm \text { SD }\end{array}$ & $0.2700 \pm 0.1120$ & $0.3202 \pm 0.0539$ & $0.0260 \pm 0.0004$ & $0.0179 \pm 0.0035$ & $0.0033 \pm 0.0015$ \\
\hline $\begin{array}{l}\text { Group II } \\
X \pm S D\end{array}$ & $0.0949 \pm 0.0181$ & $0.0372 \pm 0.0168$ & $0.0094 \pm 0.0007$ & $0.0064 \pm 0.0009$ & $0.0037 \pm 0.0006$ \\
\hline \multirow[t]{3}{*}{ Mann-Whitney test ( $p$ value) } & $0.018^{*}$ & $0.018^{*}$ & $0.015^{*}$ & $0.017^{*}$ & 0.10 \\
\hline & \multicolumn{5}{|c|}{ T3 } \\
\hline & 5 strokes & 10 strokes & 20 strokes & 30 strokes & 50 strokes \\
\hline $\begin{array}{l}\text { Group I } \\
X \pm \text { SD }\end{array}$ & $0.0093 \pm 0.0024$ & $0.00437 \pm 0.0072$ & $0.00395 \pm 0.0073$ & $0.0243 \pm 0.0083$ & $0.0029 \pm 0.0005$ \\
\hline $\begin{array}{l}\text { Group II } \\
X \pm S D\end{array}$ & $0.0910 \pm 0.0459$ & $0.0788 \pm 0.0484$ & $0.00292 \pm 0.0082$ & $0.0057 \pm 0.0010$ & $0.0011 \pm 0.0011$ \\
\hline \multirow[t]{3}{*}{ Mann-Whitney test ( $p$ value) } & 1.0 & 1.0 & 0.23 & $0.018^{*}$ & $0.011^{*}$ \\
\hline & \multicolumn{5}{|c|}{ T6 } \\
\hline & 5 strokes & 10 strokes & 20 strokes & 30 strokes & 50 strokes \\
\hline $\begin{array}{l}\text { Group I } \\
X \pm \text { SD }\end{array}$ & $0.0766 \pm 0.0289$ & $0.0362 \pm 0.0057$ & $0.0237 \pm 0.0182$ & $0.0198 \pm 0.0143$ & $0.0029 \pm 0.0004$ \\
\hline $\begin{array}{l}\text { Group II } \\
X \pm S D\end{array}$ & $0.1617 \pm 0.0065$ & $0.0939 \pm 0.0318$ & $0.0462 \pm 0.0173$ & $0.0185 \pm 0.0104$ & $0.0059 \pm 0.0016$ \\
\hline Mann-Whitney test ( $p$ value) & $0.015^{*}$ & $0.012^{*}$ & $0.045^{\star}$ & 1.0 & $0.018^{*}$ \\
\hline
\end{tabular}

*UF significantly decreased with advance time.

Table 1: Shows the difference in unmixed fraction (UF) between the numbers of chewing strokes at different observation times for both groups.

\begin{tabular}{|l|c|c|c|}
\hline & At time of overdenture insertion (T0) & 3 months after overdenture insertion (T3) & $\mathbf{6}$ months after overdenture insertion (T6) \\
\hline $\begin{array}{l}\text { Group I } \\
\text { X } \pm \text { SD }\end{array}$ & $24.5 \pm 2.25$ & $26.2 \pm 4.76$ \\
\hline $\begin{array}{l}\text { Group II } \\
\text { X } \pm \text { SD }\end{array}$ & $13.9 \pm .17$ & $11.3 \pm 2.21$ \\
\hline Mann-Whitney test (p value) & $0.018^{*}$ & $0.010^{*}$ \\
\hline
\end{tabular}

*UF significantly decreased with advance time.

Table 2: Shows the difference in retention values $(R)$ at different observation times for both groups.

of the overdenture. This has been attributed to overextension of the internal part of the clip that fastens onto the bar contour, which in turn, makes the clips flexible. For both groups, the retention values measured in Newton $(\mathrm{N})$ decreased significantly with advance of time, and this may be due to wear simulation effects as postulated by Rutkunas et al. [18], who concluded that mechanism of retention loss of resilient overdenture attachments can be explained by dimensional changes and surface alterations with advance of time. Also Uludag et al. [19] stated that with bar with clip attachment, bar with two distal locator attachments, and a bar with clear locator attachments, after 6 months of clinical function, there is a decrease in retention from the initial testing to the final pull-out test. This decrease was significant for all designs. Group I (locator bar abutments) showed a significant decrease in UF compared to Group II (barlclip attachment) after six months. Due to the high retention values compared to Group II. Group I (locatorlbar attachment) showed a significant increase in retention values (R) compared to GII at different observation times. This is due to the high retention forces obtained by locator attachments compared to all other attachments as locator attachments provide dual retention through both external and internal mating surfaces, a self-aligning feature which is helpful in guiding patients when placing their denture also require low maintenance and offer high durability and long lasting performance for over 60,000 insertion cycles Cakarer $S$ et al. [20] concluded that the locator system showed superior clinical results than the bar attachments, with regard to the rate of prosthodontic complications and the maintenance of the oral function.

\section{Conclusion}

With the limitations of this study regarding the sample size and short study periods, the following conclusions can be drawn: Despite that both types provided sufficient values in terms of retention and

Masticatory efficiency, Bar-locator retained overdenture is considered a promising prosthesis regarding retention and long term masticatory efficiency compared to Bar-clip prosthesis.

Further studies needed with additional number of patients and more investigation methods is recommended for evaluating this type of treatment modality and comparing it with others.

\section{References}

1. Kuoppala R, Näpänkangas R, Raustia A (2012) Outcome of implant-supported overdenture treatment - a survey of 58 patients. Gerodontology 29: 577-584.

2. Emami E, Heydecke G, Rompre P, de Grandmont P, Feine JS (2009) Impact of implant support for mandibular dentures on satisfaction, oral and general health related quality of life: a meta-analysis of randomized-controlled trials. Clin Oral Implants Res 20: 533-544.

3. Carlsson GE, Omar R (2010) The future of complete dentures in oral rehabilitation. A critical review. J Oral Rehabil 37: 143-156.

4. Geckili O, Bilhan $\mathrm{H}$, Mumcu E, Dayan C, Yabul A et al. (2012) Comparison of patient satisfaction, quality of life, and bite force between elderly edentulous patients wearing mandibular two implant-supported overdentures and conventional complete dentures after 4 years. Spec Care Dentist 32: 136-141.

5. Heydecke G, Thomason JM, Awad MA, Lund JP, Feine JS (2008) Do mandibular implant overdentures and conventional complete dentures meet the expectations of edentulous patients? Quintessence Int 39: 803-809. 
Citation: Shady M, Emera R, Hegazy SA, Kenawy M (2014) Bar Locator Versus Bar Clip Attachment for Implant Assisted Mandibular Overdenture. Dentistry S2: 006. doi:10.4172/2161-1122.S2-006

Page 5 of 5

6. Thomason JM, Feine J, Exley C, Moynihan P, Müller F, et al. (2009) Mandibular two-implant supported overdentures as the first choice standard of care for edentulous patients- the York consensus statement. Br Dent J 207: 185-186.

7. Gotfredsen K, Holm B (2000) Implant-supported mandibular overdentures retained with ball or bar attachments: a randomized prospective 5-year study. Int J Prosthodont 13: 125-130.

8. Tabata LF, Assunção WG, Barão VA, Gomes EA, Delben JA, et al. (2010) Comparison of single-standing or connected implants on stress distribution in bone of mandibular overdentures: a two-dimensional finite element analysis. J Craniofac Surg 21: 696-702.

9. Naert I, Alsaadi G, Van Steenberghe D, Quirynen M (2004) A ten- year randomized clinical trial on the influence of splinted and unsplinted oral implants retaining mandibular overdentures: peri-implant outcome. Int J Oral Maxillofac Implants 19: 695-702.

10. Stanford CM (2007) Dental implants: a role in geriatric dentistry for the general practice? J Am Dent Assoc 138: 34-40.

11. Kurtzman GM (2008) Lab techniques for use of the LOCATOR attachment in baroverdenture applications. Teamwork. The Insider's Guide to Quality Dentistry.

12. Schneider Al, Kurtzman GM (2001) Bar overdentures utilizing the locator attachment. Gen Dent 49: 210-214.

13. Schimmel M, Christou P, Herrmann F, Müller F (2007) A two-color chewing gum test for masticatory efficiency: development of different assessment methods. J Oral Rehabil 34: 671-678.

14. Burns DR, Unger JW, Elswick RK Jr, Beck DA (1995) Prospective clinica evaluation of mandibular implant overdentures: Part I retention, stability, and tissue response. J Prosthet Dent 73: 354-363.

15. Prinz JF, Lucas PW (1997) An optimization model for mastication and swallowing in mammals. Proc RSoc Lond B 264:1715-1721.

16. Weijenberg RA, Scherder EJ, Visscher CM, Gorissen T, Yoshida E, et al. (2013) Two-colour chewing gum mixing ability: digitalisation and spatial heterogeneity analysis. J Oral Rehabil 40: 737-743.

17. Van der Bilt A, van Kampen FM, Cune MS (2006) Masticatory function with mandibular implant-supported overdentures fitted with different attachment types. Eur J Oral Sci 114: 191-196.

18. Rutkunas V, Mizutani H, Takahashi H, Iwasaki N (2011) Wear simulation effects on overdenture stud attachments. Dent Mater J.

19. Uludag B, Polat S (2012) Retention characteristics of different attachment systems of mandibular overdentures retained by two or three implants. Int $J$ Oral Maxillofac Implants 27: 1509-1513.

20. Cakarer S, Can T, Yaltirik M, Keskin C (2011) Complications associated with the ball, bar and Locator attachments for implant-supported overdentures. Med Oral Patol Oral Cir Bucal 16: 953-959. 